\title{
Avaliação Institucional e da Aprendizagem na Escola de Ensino infantil e Fundamental Joaquim Caboclo
}

\author{
Erasmo Gonçalo Dias ${ }^{1}$; Gislene farias de Oliveira $^{2}$
}

\begin{abstract}
Resumo: O presente artigo tem o objetivo de apresentar diferentes conceitos de avaliação. Também mostrar a compreensão de avaliação e, como esta vem sendo desenvolvida pelos professores que atuam no Programa de Alfabetização na Idade Certa-PAIC da Escola de Ensino Infantil e Fundamental Joaquim Caboclo, no Distrito de Miragem Caririaçu-CE. Faz-se um paralelo com as avaliações externas como, SPAECE e a PROVA BRASIL. Traz alguns recortes teóricos de autores sobre a questão, comungando especialmente com as ideias de Oliveira, Luckesi, Demo, Hoffman e Luck, dentre outros. A metodologia da pesquisa é qualitativa, através de revisão bibliográfica e documental. Os documentos oficiais da escola e os dados acerca das avaliações, foram coletados junto aos professores da referida escola, por ocasião do planejamento escolar, nos dias 19 e 20 de maio de 2016 . Apresenta portanto grande relevância, pois poderá servir como fonte bibliográfica norteadora acerca de como realizar uma avalição que supere a visão minimizada de separar os alunos por competência e que usa a avaliação como instrumento de tortura e ferramenta de controle de turma, resumindo a avaliação a simples exames.
\end{abstract}

Palavras-chave: Aprendizagem. Avaliação. Educação.

\section{Institutional and Learning Evaluation in the Elementary and Secondary School Joaquim Caboclo}

\begin{abstract}
This article aims to present different concepts of evaluation. Also show the understanding of evaluation and how it has been developed by the teachers who work in the Literacy Program in the Right Age-PAIC of the Joaquim Caboclo Elementary School, in the District of Miragem, Caririaçu-CE. There is a parallel with external evaluations such as SPAECE and PROVA BRASIL. He brings some theoretical writings on the subject, especially with the ideas of Oliveira, Luckesi, Demo, Hoffman and Luck, among others. The methodology of the research is qualitative, through bibliographical and documentary revision. The official school documents and data about the evaluations were collected from the teachers of that school, on the occasion of school planning, on May 19 and 20,2016 . It is therefore of great relevance, since it can serve as a guiding bibliographic source about Of how to carry out an evaluation that surpasses the minimized vision of separating the students by competence and that uses the evaluation like instrument of torture and tool of control of class, summarizing the evaluation to simple exams.
\end{abstract}

Keywords: Learning. Evaluation. Education.

\footnotetext{
${ }^{1}$ Mestrando em educação pela Anne Sullivan University - Polo Juazeiro do Norte . E-mail: erasmodias76@ gmail.com;

2 Psicóloga. Doutora em psicologia Social pela Universidade Federal da paraíba - UFPB. Pós Doutorado em Ciências dea Educação pela Faculdade de medicina do ABC - SP. Professora da Universidade Federal do Cariri - UFCA. E-mail: gislenefarias@ gmail.com.
} 
Id on Line Revista Multidisciplinar e de Psicologia

Id on Line Multidisciplinary and Psycology Journal

\section{Introdução}

De todos os desafios a que a escola tem enfrentado, a avaliação parece ser o mais latente e que por isso tem sido um tema bastante debatido entre professores e todos os segmentos que compõem a educação do nosso país. De um modo geral os professores apresentam sérias dificuldades na hora de avaliar, pois sobre estes, existe toda uma carga histórica em que a avaliação ficou minimizada a testes e exames de extremo rigor. De acordo com Luck (2012 p. 125) "Nenhuma prática de avaliação é enfrentada sem passar pela superação de dificuldades, obstáculos e limitações”. Assim a avaliação é sem dúvida um dos principais gargalos a ser superados dentro das escolas brasileiras.

Sendo a avaliação um tema de extrema complexidade, pretende-se com este artigo apresentar as ideias de autores como Oliveira(2014); Cipriano Luckesi (2001/2002); Pedro Demo(2008); Jussara Hoffmann (2001); Heloisa Luck (2012); Brasil (2002); entre outros que dissertam acerca da temática de forma a mostrar caminhos que podem contribuir com a prática pedagógica, enfatizando é claro, que nenhum método avaliativo é perfeitamente transferível para uma realidade desconexas dos fatos, do contexto e dos objetivos propostos, carecendo com isso ser discutido, compreendido e se possível adaptado e incorporado a uma dada realidade, para assim servir de ferramenta de superação de desafios encontrados.

O presente artigo de abordagem qualitativa além da introdução, apresenta mais quatro pontos. No segundo ponto, busca-se apresentar os principais conceitos de avalição, seja estas ditas institucional, internas ou da aprendizagem e externas como Prova Brasil, Spaece, etc.

No terceiro ponto é mostrado como os professores que atuam no paic da E.E.I.F. Joaquim Caboclo em Vila Miragem Caririaçu-CE, tem avaliado seus alunos e qual a compreensão de avaliação que estes educadores têm, apresentando um paralelo entre os diferentes conceitos de avalição.

Finalmente, as considerações finais em que são apresentados as principais contribuições do artigo, considerado de grande relevância, pois poderá servir como fonte bibliográfica norteadora acerca de como realizar uma avalição que supere a visão minimizada de separar os alunos por competência e que usa a avaliação como instrumento de tortura e ferramenta de controle da turma. 
Id on Line Revista Multidisciplinar e de Psicologia

Id on Line Multidisciplinary and Psycology Journal

Do contrário, busca-se semear entre os educadores um fazer pedagógico avaliativo diferente onde Luckesi (2001), o ato de avaliar seja um ato solidário com o educando na busca do seu desempenho mais satisfatório, e, com isso humanizado. Assim, trabalhando na defesa de uma avaliação formativa, que rampa com as amarras que impede o crescimento do educando, possibilitando com isso um fazer verdadeiramente democrática, de modo que no ato avaliativo o aluno possa refletir sobre suas próprias mudanças.

\section{Conceituando Avaliação}

Geralmente entende-se por avaliação um julgamento sobre algo em que medimos numericamente ou através de atribuição de conceitos o grau de evolução ou não de um e/ou grupos de indivíduos. A LDB, Lei de Diretrizes e Bases da Educação Nacional em seu Art. 24 inciso V versa que: “a verificação do rendimento escolar observará os seguintes critérios: a) avaliação contínua e cumulativa do desempenho do aluno, com prevalência dos aspectos qualitativos sobre os quantitativos e dos resultados ao longo do período sobre os de eventuais provas finais; [...]” (BRASIL, 2001, p.21).

O cotidiano do professor deve ser embebido de uma boa prática avaliativa, pois é a partir da avaliação que se projeta os rumos da ação, apontando para a transformação do meio, onde esta servirá portanto de mediação no processo de ensino aprendizagem, primando sempre pela evolução qualitativa do educando. Nesse sentido, comungamos com as ideias de Werneck (1999, p. 47) ao dizer "que essa qualidade, essa excelência, seja, antes de mais nada, uma excelência humana".

É necessário lembrar que existem diferentes tipos de avaliação e que aqui procuraremos apresentar de modo sucinto como estas se incorporam no cotidiano escolar, procurando elucidar algumas das questões que as circundam, especialmente no que tange a avaliação institucional, avaliação da aprendizagem e/ou a avaliação externa. Muito embora estas se entrelacem sendo comumente tratadas como únicas e indistintamente, existem grandes diferenças entre elas, principalmente no que se refere às suas aplicabilidade e aos seus objetivos.

Avaliação da aprendizagem está intimamente ligada com o fazer pedagógico, fazendo parte portanto do dia a dia do professor, estando assim presente desde o planejamento que 
antecedo a execução da aula, até os rumos finais que concretiza o que foi mensurado. Nesse sentido, a avaliação subsidia, serve a uma ação, tendo em vista, com ela, obter o melhor resultado possível (LUCKESI, 2002). Com isso projeta-se novos objetivos com o intuito de preencher lacunas e/ou lançar mão para a busca de novos saberes.

Nesse processo, embora esta aconteça necessariamente em sala de aula, envolve vários segmentos, como afirma a autora quando diz que:

\begin{abstract}
$\mathrm{Na}$ avaliação da aprendizagem, quem exerce o papel de avaliar é o professor e o avaliado passa a ser o aluno; na do sistema, a avaliação é assumida pelo Estado e alunos, professores, escola e família serão os avaliados; por fim, na avaliação institucional é a comunidade escolar quem planeja, executa, avalia e toma decisão; portanto pode-se considerá-la uma relação de mão dupla, de reciprocidade (OLIVEIRA, 2014, p.5).
\end{abstract}

Para diferentes tipos de metas e objetivos propostos, busca-se um tipo de avaliação capaz de responder com o que se propõe encontrar, ou seja, se o que buscamos é específico a determinado conteúdo, os agentes envolvidos são professores que de forma direta municia-se de instrumentos de coletas de dados para este fim. Se de outro lado o que pretende-se é o todo, referente as condições gerais da escola em que envolve professores, alunos e comunidade, esta é assumida pelo Estado, lançando mão de instrumentos específicos para responder ou não com as hipóteses anteriormente estabelecida, pois toda e qualquer avaliação antecede-se um diagnóstico que a direcione, sendo este portanto, um tipo de avalição prévia.

No que se refere a avaliação de larga escala que tem como foco a aprendizagem, este vem sendo uma das principais ferramentas do Estado para medir em que nível a Educação Básica do país se encontra nos anos terminais de cada ciclo de estudo, ou seja, com exceção do $2^{\circ}$ ano do ensino fundamental, esta acontece no término do $5^{\circ}$ e $9^{\circ}$ ano do ensino fundamental.

Porém, mesmo que esta seja uma avaliação externa, é um tipo de avaliação que envolve todos os setores da escola de modo a não perder de vista os objetivos para esse fim.

\footnotetext{
A avaliação da aprendizagem na Educação Básica no Brasil é uma prática consolidada a partir da década de 90 com o Sistema de Avaliação da Educação Básica - SAEB. A utilização da Prova Brasil (alunos concluintes do $5^{\circ}$ e $9^{\circ}$ anos de escolarização) e da Provinha Brasil (alunos do $2^{\circ}$ ano de escolarização) com a divulgação dos índices de desempenho obtidos pelas escolas, busca avaliar o ensino público brasileiro, contribuindo para melhorar a qualidade do ensino oferecido. São avaliações externas organizadas pelo Ministério da Educação através do Instituto Nacional de Estudos e Pesquisas Educacionais Anísio Teixeira - INEP (OLIVEIRA, 2014, P.6).
} 
Com isso denomina-se avaliação externa pelo fato de não ser planejada e executada pelo escola e, principalmente, pelo professor, mesmo que estes elaborem metas em consonância com o que se propõe essas avaliações. Muitas vezes, de modo até exagerado, as aulas pautam-se meramente em torno dessas avaliações, secundarizando todas as especificidades a que se encontra a turma.

Não considerar as especificidades a que se encontra as escolas brasileira, parece ser um dos principais gargalos desse tipo de avaliação, pois fica difícil conceber que uma mesma prova seja aplicável em qualquer escola, pois em um país de dimensões continentais como o Brasil e com tantas diversidades culturais e gritantes diferenças econômicas e sociais, avaliar através de um único instrumento (no caso os exames) é no mínimo uma grande contradição.

\begin{abstract}
Não é possível pensar em um único modelo de avaliação que atenda a todas as escolas, porque para que ele ganhe significado institucional, precisa responder ao projeto educacional e social em curso. Portanto, cada escola ou rede de ensino irá construir a sua proposta de avaliação, a partir de um processo dialógico e negociação de intenções, propósitos e alternativas de ação (SOUSA, 2011, p. 24).
\end{abstract}

A própria implantação dessas avaliações, passam a propositar entre os segmentos escolares a exigências e a tomada de novas posturas frente a como estas vem se desenvolvendo e evoluindo ou longo de sua da história. Com isso, mesmo que esses exames sejam necessário, pois carece o Estado ter uma visão globalizada de como os alunos tem se encontram em nível de aprendizagem, avalição de sala de aula não pode se tornar uma versão reduzida dessas provas anuais. Por isso, a ocorrência de constantes revoltas em torno dessa questão, que vem gerando um apanhado de reflexões aceitáveis no interior da escola pública.

Nesse sentido, ainda referente a avaliação da aprendizagem, é bom enfatizar que o que está em questão não pode ser meramente os bons índices, que muitos vezes demonstram uma frieza em taxar resultados sem análise do contexto e das adversidades inerente a todo fazer pedagógico. Com isso, é importante colocar que mais que a quantidade, esta deve buscar sempre ser otimizada de modo a culminar numa avaliação qualitativa. A esse respeito, o autor diz que:

A avaliação qualitativa deve levar em conta principalmente a qualidade de vida atingida e o envolvimento: Na qualidade não vale o maior, mas sim o melhor; não é o extenso, mas sim o intenso; não é o violento, mas sim o envolvente; não é a pressão, mas sim a impregnação. Qualidade é de estilo cultural, mais que tecnológico; artístico, 
mais que produtivo; lúdico mais que eficiente; sábio mais que científico (DEMO, 2008, p. 13).

Desse modo é importante que toda escola, especialmente todo professor, incorpore o espírito de uma avaliação centrada no fazer bem ao aluno, de maneira que este, não seja simplesmente um número com classificação boa ou ruim, mas sim, que possa ter liberdade de evoluir em sua plenitude.

Nesse caminho o professor deve tomar a postura de um indivíduo mediador, vendo de perto todas as nuances que possibilita o crescimento do grupo. Assim, "[...] quando se acompanha para ajudar no trajeto, é necessário percorrê-lo juntos, sentindo-lhe as dificuldades, sugerindo rumos adequados a cada aluno HOFFMANN (2001, p.89)". Com isso, de maneira a orientar os cominhos que serão trilhados durante o processo de construção do conhecimento de cada educando, fortalecendo assim, uma avaliação sem repressão e com capacidade de emancipar.

Uma outra via avaliativa desrespeito a avalição institucional realizada por agentes externos à escola, é abrangente e não se limita em um ponto específico, tendo portanto objetivos que embora tenho como foco a melhoria da qualidade do ensino, esta avaliação, não se dá de forma direta. Nesse sentido, para melhor fundamentar a questão recorremos as contribuições da autora enfatizando que:

\footnotetext{
A avaliação institucional da escola consiste em um processo sistemático, abrangente e contínuo de observação, coleta e análise de dados, interpretação e julgamento da realidade e prática escolares, em seus desdobramentos e interações, tendo por objetivo contribuir para a melhoria contínua do trabalho educacional e seus resultados (LUCK 2012, P.39).
}

Assim, compreender esse processo avaliativo é de extrema importância para todos os segmentos que compõe a escola pública, servindo portanto, de fio condutor de todos os processos que cerca a escola, pois a partir da avaliação institucional é que se projeta metas que vislumbrem a elucidação de problemas existentes no interior da escola.

\section{Resultados e Discussão}


Id on Line Revista Multidisciplinar e de Psicologia

Id on Line Multidisciplinary and Psycology Journal

\section{Como avaliam e qual a visão de Avaliação dos professores que atuam no $5^{\circ}$ ano do Programa de Alfabetização na Idade Certa-PAIC da E.E.I.F. Joaquim Caboclo}

É penoso dizer que a forma que comumente se avalia nas escolas brasileiras, são ainda resquícios do método avaliativa a qual adotou os jesuítas no início do processo de escolarização do nosso país. Mesmo sem poder apresentar números precisos, tal afirmativa continua lamentavelmente sendo uma prática corriqueira entre professores da Escola de Ensino Infantil e Fundamental Joaquim Caboclo, sediada na zona rural da pequena cidade de Caririaçu, interior do cariri cearense.

Os dados levantados em uma pesquisa apontou que além das sérias dificuldades em avaliar, os professores não detêm os conhecimentos teóricos mínimos que os habilitem a realizar uma avaliação centrada no educando. Na contramão do que pensa Luckesi (2002), em afirmar que "os conhecimentos não deverão ser súmulas de informações que devam ser assimilados e repetidos em provas, mas sim compreensão da vida no seu dia a dia". Para eles os conteúdos devem ser repassados tal como manda o currículo e que assim devem ser cobrados para saber se o aluno aprendeu, transformando este aprendizado em números de forma que habilite ou não o aluno a passar de ano.

Perguntado sobre como estes avaliam seus alunos no cotidiano escolar, dos três professores que atuaram nos últimos cinco anos no $5^{\circ}$ ano do Ensino Fundamental, responderam que passam os conteúdos e depois os cobram em forma de trabalhos e provas com questões fechados, afirmando que realizam as provas no mesmo estilo das avaliações externas, precisamente no formato da Prova Brasil e Spaece.

O cotidiano da sala de aula funciona como um campo de treinamento dos conteúdos que pode vir a cair nos exames externos ao contexto escolar, ou seja, toda a escola se mobiliza para "se sair bem" em dois "míseros" exames que acontecem no final do ano letivo e tudo o que acontece nesse entremeio, são apenas testes preliminares sem valor aparente. Com isso é disseminada a ideia de que os exames são avaliações, e como afirma Luckesi (2002), são apenas instrumentos de coleta de dados, que com um toque pedagógico podem ser usados para mudar a ação, configurando-se portanto se bem planejados, em avaliação.

Assim compreendendo a avaliação, podemos concluir que os exames possuem outras características diferentes, até mesmo opostas às da avaliação. Os exames não diagnosticam, mas sim classificam. E, por serem classificatórios, obrigatoriamente são seletivos, o que quer dizer excludentes. Veja o exame vestibular, ou um exame 
para um concurso qualquer. A sua função é selecionar, incluindo alguns e excluindo muitos. Um exame não avalia, ele seleciona; consequentemente, não subsidia a tomada de decisão para a reorientação (LUCKESI, 2001, p. 2).

Contrariamente à afirmação acima, percebe-se a satisfação da escola e dos professores em ranquear turmas, premiando os alunos que obtiveram as melhores notas nos exames preliminares que acontecem mensalmente, prometendo presentes, passeios e grandes festas caso a turma obtenha bom êxito no Spaece.

Ao formular indagações acerca da base teórica norteadora em que realizam suas avaliações, estes simplesmente colocam que aprenderam na prática, que passaram por esse mesmo processo e que essa é a principal maneira de fazer com que o aluno progrida, evolua e aprenda. Até porque, “as provas são o meio de entrada nos cursos superiores e que é necessário classificar, ranquear, selecionar pois é exatamente isso que o aluno irá se deparar na vida real". Afirmaram também, que o nome deles é quem estar em jogo, pois o professor é valorizado ou não de acordo com os resultados obtidos nesses exames dessas avaliações externas.

Questionado a respeito de um viés avaliativo mais coerente e compatível com a realidade da escola como defende o autor apresentando que:

\begin{abstract}
A avaliação da aprendizagem escolar adquire seu sentido na medida em que se articula com um projeto pedagógico e com seu consequente projeto de ensino. A avaliação, tanto no geral quanto no caso específico da aprendizagem, não possui uma finalidade em si; ela subsidia um curso de ação que visa construir um resultado previamente definido. No caso que nos interessa, a avaliação subsidia decisões a respeito da aprendizagem dos educandos, tendo em vista garantir a qualidade do resultado que estamos construindo. Por isso, não pode ser estudada, definida e delineada sem um projeto que a articule (LUCKESI, 2001, P. 71).
\end{abstract}

No oposto a essa linha, foram pontuadas e/ou alegadas várias impossibilidades, como por exemplo dito que: "Não podemos dissociar as avaliações do governo (Spaece), das que realizamos em sala de aula, pois uma deve ser o retrato da outra, o mesmo modelo, pois os conteúdos são os mesmos; Todas as reuniões e planejamentos só se fala nessas benditas provas, por isso não temos como fazer diferente; Os projetos só servem para maquiar as coisas, o que importa é sempre o resultado final da prova; O Projeto Político Pedagógico estar engavetado a séculos, é simplesmente um enfeite". E tantas outras colocações em que desfigura o real sentido da avaliação, limitando-a a exames que reafirmando o que diz Luckesi (2002), são meros instrumentos de coleta de dados. Desse modo, não subsidiando a ação pedagógica qualitativa, 
Id on Line Revista Multidisciplinar e de Psicologia

Id on Line Multidisciplinary and Psycology Journal

secundarizando com isso o real sentido da avaliação que é o de garantir a qualidade do ensino e como consequência a aprendizagem.

\section{Considerações Finais}

As diferentes concepções de avaliação a qual discorremos ao longo deste artigo, ganham validade e corporeidade a partir do comprometimento que ficou estabelecido entre seus agentes envolvidos, no caso específico entre o pesquisador das fontes bibliográficas aqui apresentadas e os professores da Escola de Ensino Infantil e Fundamental Joaquim Caboclo, pois após todos estes questionamentos, o artigo ficará à disposição para possíveis discussão em grupo focal, servindo portanto de fonte bibliográfica norteadora de reflexão entre os pares.

É importante salientar, que embora pudéssemos reunir aqui autores consagrados em torno da temática avaliação e o assunto comumente rodei o ambiente escolar, tal questão não deve ser considerada ainda como saturada, pois faz parte do próprio processo avaliativo rever, reanalisar, refletir e retomar determinadas questões para assim direcionar novas ações em torno dos objetivos que outrora fora propostos.

Assim, fica evidente que a avaliação serve de base de sustentação de tudo que demanda da escola, seja ela institucional que de forma ampla busca equalizar parte dos problemas educacionais; da aprendizagem, que a título de sugestão de preferência formativa/qualitativa que subsidie, que emancipe, enfim, que faça bem ao aluno de forma plena, fazendo-o compreender-se enquanto indivíduo.

\section{Referências}

BRASIL. Lei Darci Ribeiro (1996). LDB: Lei de Diretrizes e Bases da Educação Nacional: Lei no 9.394 de 1996 - 2. ed. - Brasília: 2001.

HOFFMANN, Jussara. Avaliação: mito \& desafio: uma perspectiva construtivista. Porto Alegre: ed. Mediação, 1991.

Avaliação mediadora: uma prática em construção da pré-escola à universidade. Porto Alegre: ed. Mediação, 1993. 
Id on Line Revista Multidisciplinar e de Psicologia

Id on Line Multidisciplinary and Psycology Journal

LÜCK, Heloísa. Perspectivas da avaliação institucional da escola. Rio de janeiro: ed. Vozes, 2012.

LUCKESI, Cipriano Carlos. Verificação ou Avaliação: O Que Pratica a Escola? CAED. Gestão e avaliação da educação pública. Gestão do currículo. 2001.

Eccos Revista Científica, vol. 4, fac. 02, Universidade Nova de Julho, São Paulo, pág. 79 a 88, 2002. Website:www.luckesi.com.br.

OLIVEIRA, Cleide. Avaliação institucional na educação básica: limitações e possibilidades. São Paulo, 2014.

SOUSA, Sandra Zákia L. Debater é preciso. In: Avaliação educacional - em busca de critérios justos - a construção de uma ação significativa. Revista Escola Pública - Editora Segmento, p. 16-29, set/2011.

WERNECK, Hamilton. Se a boa escola é a que reprova, o bom hospital é o que mata. $5^{\mathrm{a}}$ ed. DP\&A - Rio de Janeiro, 1999.

Como citar este artigo (Formato ABNT):

DIAS, E.G.; OLIVEIRA, G. F. Avaliação Institucional e da Aprendizagem na Escola de Ensino Infantil e Fundamental Joaquim Caboclo. Id on Line Revista Multidisciplinar e de Psicologia, Janeiro de 2017, vol.10, n.33, p. 337-346. ISSN: 1981-1179.

Recebido: 08/12/2016

Aceito: $12 / 12 / 2016$ 